\title{
THE COMPLICATIONS OF OSTEITIS DEFORMANS
}

\author{
By Bernard Lennox, M.D. \\ Department of Pathology, Post Graduate Medical School of London
}

Paget's disease of bone was formerly regarded as a rarity. In the 24 years following its first description in 1877 only 66 cases were published (Packard et al., 1901) and these probably were very nearly all the cases diagnosed in the world. Now single clinics can produce series of over a hundred cases. This hospital has admitted 88 cases in the last ten years and the disease is becoming almost a commonplace of the wards. Improved diagnosis, especially radiological, is chiefly responsible for this, but the steady ageing of our population is also an important factor. Paget's disease is very largely a disease of the elderly and must take its share of the increasing interest in geriatric problems.

The general picture of the disease, especially of the skeletal changes, is familiar. The multiplicity of secondary effects of these bony lesions is not perhaps so widely realized. They are important, however, for the presenting symptom of Paget's disease is more often a complication than the disease itself, and although for the disease itself only symptomatic treatment is available, some of the complications demand active measures.

Paget's original clinical description (1877) is still unsurpassed. On the more general aspects of the disease Snapper (1943) gives the best recent review. On the aetiology much has been written but little of value has emerged ; it is best to confess ignorance. On the pathology Higbee and Ellis (191 I), Knaggs (1926), Schmorl (1926, 1930, 1932) and Jaffe (1933) have contributed most.

The best recorded modern series are those of O'Reilly and Race (1932) and Kay et al. (1934). Kay (1930), Gutman and Kasabach (1936) and Reifenstein and Albright (1944) cover the biochemistry and Koller (1946) the genetics.

The present account is chiefly based on a search of the literature of the disease, both old and new, which was originally undertaken for another purpose. This has been reinforced by a study of the material at Hammersmith Hospital. Autopsies have been made on ${ }_{5} 5$ cases of extensive Paget's disease ( 0.34 per cent. of $4,45^{\circ}$ post mortems in $13 \frac{1}{2}$ years). Clinical records are available of 88 cases for the ten years $1938 / 47$ (0.12 per cent. of 76,000 admissions).

It may be worth while considering parentheti- cally the extraordinary variation in figures for the incidence of the disease. They vary from 3 per cent. (Schmorl, 1932) to 0.013 per cent. (Koller, 1946). The reasons for this need not be detailed but are obvious enough when one studies the series concerned ; they emphasize, however, the difficulty of any statistical study and are the principal reason why no attempt has been made here to assess in any but the broadest terms the incidence of the various complications.

\section{Classification of Complications}

One may classify complications by systems, but for the present purpose it is of greater service to use a pathogenetic classification based on the way in which the complication derives from the original disease :-

I. Local effects.

I.I Fractures.

I.2 Osteosarcoma.

I.3 Effects on other systems produced by the enlarged and distorted bones.

I.3I Arthritis (?).

I.32 Pressure effects on the nervous system.

I.32 I VIIIth nerve.

I.322 Other cranial nerves.

1.323 Posterior fossa (basilar invagination).

I.324 Spinal cord.

r.33 Effects on nose, sinuses and jaws.

I.34 Thoracic deformity (?).

2. General effects.

2.I Disorders of calcium metabolism.

2.I I Hypercalcaemic episodes and acute metastatic calcification.

2.12 Arterial calcification.

2.13 Heart valve calcification and heart block.

2.14 Calcification of avascular structures.

2.I 5 Renal calculi (?).

2.2 Endocrine disorders (?).

2.3 Effects of the arteriovenous shunt through vascular bones.

2.3 I High output heart failure.

2.32 Varicose veins (?). 
A distinction of immediate practical importance may be made between the two main groups. The local effects may be seen in cases with localized or even monostotic disease ; the general effects only appear in cases with many bones involved.

\subsection{Fractures}

Surprise has often been expressed at the ease with which the thick and heavy bones of Paget's disease are fractured. The radiologist, who can see loss of trabecular structure, is less likely to be surprised than the clinician, and the pathologist, who can handle the bones, even less so. At post mortem it is obvious that the bones have entirely lost their characteristic temper, the steely hardness and elasticity of normal bone giving place to a brittle frangibility like that of soft sandstone. At its best (or most sclerotic) the bone breaks like cast iron; at its worst (or most osteoporotic) like Edinburgh rock. The skull cap shown in Fig. I, twice the normal thickness, broke clean away from the base while being sawn; in another case the iliac crest was broken between finger and thumb. Wolff's law (" the structure of bone is governed by its function') no longer operates, and the bone is a mass of osseous tissue, abundant enough but not organized to resist strain.

Transverse zones of radiolucency in the convex margin of the femur, well seen in Fig. 2, are sometimes a source of fracture (Reifenstein and Albright, 1944). Schmorl (1932) showed (but this has yet to be confirmed) that they are partial fractures (or 'infractions') which are slow to heal completely. He believed that they are responsible for the bowing of a bone without decrease in length which can sometimes be demonstrated. They must not be confused with the rather similar Looser's nodes of osteomalacia.

The actual frequency of fracture in Paget's disease may be exaggerated and its significance has even been denied. As will be pointed out later in connection with renal calculi, in any condition in which $\mathrm{X}$-rays are a routine, the examination will bring to light many unsuspected and possibly incidental cases of Paget's disease. But apart from the a priori probabilities, a study of cases in which fractures occur repeatedly through affected bones, sparing normal bones, is very strong evidence that the association is real (Rogers and Ullin, I936). 'Our 88 cases at Hammersmith included seven with fractures (Fig. 3 ).

Fractures usually involve the lower limb or pelvis, sometimes the vertebrae or humerus, apparently never the skull. Transverse fractures just below the greater trochanter and of the upper third of the tibia are especially common. They are rarely quite spontaneuous but result from relatively minor trauma. Pain is often remarkably slight.
Treatment presents no unusual difficulties, though Kuntscher nailing for the subtrochanteric fracture and the Smith-Petersen pin for fractures of the femoral neck cannot be used. Callus is formed abundantly; union is rarely delayed and may be exceptionally rapid; the vascularity and cellularity of the bone are presumably responsible for this. Vitamin D and a high calcium diet may be dangerous, as will be shown later (see 2.I I).

A fracture may be the first sign of sarcoma (Fig. 4).

\subsection{Osteosarcoma}

Paget's original case (1877) died of a sarcoma of the radius with lung metastases (it has been unkindly suggested that this was a lung carcinoma with bony secondaries, but on no very good grounds). In a later paper (1889) Paget stated that he had followed eight cases to death and five of these had died with tumours of some sort. Sarcoma and carcinoma were not clearly distinguished in his day, and he seems to have believed that tumours in general were unusually frequent. There is no evidence in any recent work of increased frequency of any tumour but bone sarcoma.

The old controversy on this subject is now only of historical interest. Since Coley and Sharpe's demonstration (I93I) that 28 per cent. of bone sarcomata in those over the age of 50 occur in bones affected by Paget's disease no one doubts the reality of the relation. Sarcoma is so rare in normal bones in the elderly that one is surprised that their figure is no higher than 28 per cent.

The exact incidence of sarcoma remains uncertain. The available larger series of cases show a low incidence of sarcoma, but on closer examination- this loses significance. The only large pathological series (Schmorl, I932) consists mainly of cases with minimal lesions, which do not develop sarcomata. The large clinical series of O'Reilly and Race (1932), Kay et al. (1934), Gutman and Kasabach (1936), Sugarbaker (1940), Nichols and Raines (I94I) and Newman (1946) contain a high proportion of cases of extensive disease and very few sarcomata, but what is recorded in each case in these series is usually only a single study at the time of first diagnosis. Sarcoma commonly forms only a brief episode at the end of a prolonged disease during which many patients pass out of the sight of those who have made the original diagnosis. Only an analysis of the actual causes of death in a large series of cases will give a reliable figure, and none is available. Our own autopsy records show two sarcomata among I 5 cases, and of the 30 other cases with full autopsy reports collected by Harrison and Lennox 
(1948), seven had sarcomata. The incidence suggested by these figures is probably exaggerated by the 'news value' of the sarcomata, but it seems probable that as many as ro per cent. of cases of extensive Paget's disease die of osteosarcoma.

Men are four or five times as often affected as women though Paget's disease itself has no sex bias and osteosarcoma in the mass only a slight male bias. The average age of onset in the 76 cases collected by Sumney and Pressly (1946) is $5^{8}$ years, with a range from $32-78$. The femur is the commonest site, closely followed by the humerus, skull and tibia. The tumours occur occasionally in other bones, but have not been reported in the fibula or sternum or in the hand, foot or face bones. They are frequently multiple ; in 26 of Sumney and Pressly's 76 cases more than one bone was involved. The possibility that multiple tumours arise by metastasis from a single primary can be discounted in most of these cases. Von Albertini (I929) showed that even in a case with only a single sarcoma there may be multiple foci of premalignant osteoblastic proliferation. The first symptom is often a fracture (Fig. 4) and though this is usually obviously an effect of the tumour, in some cases the time relations have been such as to suggest that it may have been a cause. One cannot, however, escape a suspicion that in some of these cases the tumour has been missed in the earliest radiographs.

The histology of these tumours is unremarkable. Most are poorly differentiated osteosarcomata, but pure fibrosarcoma has been reported and one of our cases had massive lung metastases of well differentiated osteochondrosarcoma. Everything points to an origin from osteoblasts and to continuous osteoblastic stimulation as the cause.

The prognosis is at present hopeless, and no cures have been reported. This is the more surprising in that osteosarcoma arising in normal bones shows a rather better prognosis than usual in the higher age groups (Badgely and Batts, 194I). Late diagnosis (the symptoms being ascribed to the pre-existing disease) is one factor and multiple tumours another, but the tumours seem to be exceptionally malignant. Platt's case (1946/7) with a two-year survival is quite unusual.

\subsection{Arthritis}

Osteoarthritis is common in sufferers from Paget's disease, but it has not been shown to be commoner than in control series of the same age. It is, in fact, remarkable how little gross bone changes may effect the related joints.

\subsection{Pressure Effects on the Nervous System}

The soft tissues are remarkably resistant to damage by the enlargement and distortion of the bones. Arteries and veins have, to the writer's knowledge, never been proved to be obstructed in this way. The meningeal vessels may become almost buried in the bone of the thickened skul cap (Fig. Ib) but remain perfectly permeable. Considering the close investment of much of the nervous system by bone, nervous complications might be expected to be frequent, but except for deafness they are in fact uncommon. They do however, occur in considerable variety, can present some interesting diagnostic problems and are sometimes amenable to surgical treatment.

\section{I.32 I. VIIITH NeRVE}

The position of the ear is exceptional, for it is more intimately related to bone than any other nerve structure. Indeed it is, strictly speaking, wrong to classify this as a pressure effect on the nervous system, for here we are dealing with a direct disorganization of the receptor.

Deafness of some degree is common enough to be a reliable sign of the disease. Newman (1946) found it in 20 of 82 cases. Tamari (I94I) claims it to be demonstrable in all cases with skull in volvement, and this is probably no great exaggeration. It may be of conductive or nerve type but is usually mixed; vestibular function is less in volved than hearing. Loudness recruitment tests have not been recorded. The pathology has beeff the subject of several painstaking studies (Tamari) but, except that the lesion lies chiefly in the cochlea and not in the VIIIth nerve itself, the results seem inconclusive. Probably deformity of the bony framework of the inner ear is the real trouble, though Brunner and Grabscheid (1936/7) believed they had demonstrated a serous inflammation. In the type of deafness and in some pathological features there are similarities to otosclerosis, and it has even been suggested (Jenkins, 1923) that otosclerosis is a localization in the petrous temporal of Paget's disease.

\subsection{Other Cranial Nerves}

Other cranial nerves may be affected. Anosmia is second only to deafness in frequency, if Guillain and Messimy's work (1939) is accepted. Amblyopia is often mentioned as a complication but has not been studied in detail. It was an important feature in two of Newman's 82 cases and one of our 88. It is usually of ' retro-bulbar neuritis' type, with peripheral and often central scotomata. Postic (1940) records a case with radiological evidence of narrowing of the optic foramen. Some other eye lesions such as transverse opacity of the cornea (Cass, 1939) and tigroid fundi have been recorded but may be coincidences.

Pierre Marie and Léri (Léri, 1913) demonstrated 
narrowing of the foramina at the base of the skull and believed that this was the cause of the nerve lesions, but it seems likely that stretching of the nerves due to distortion of the base of the skull is at least as important. It is noteworthy in this connection that in spite of its long intra-osseous canal, the VIIth nerve is one of the least often affected.

Cranial nerve involvement is sometimes multiple. If this occurs in the presence of gross cranial deformity (Gregg, 1926) diagnosis is easy, but much more difficulty will be found when, as sometimes happens (Lehoczky, 1939), the bone lesions are limited to the cranial base.

\section{I.323. Basilar InVAgination}

Distortion of the base of the skull in Paget's disease is common and can be important. The heavy and plastic skull, supported over too small an area by the cervical vertebrae, droops down and produces a tam-o'-shanter effect. Seen from inside, the effect is one of a central boss protruding into the cranial cavity from below, its apex at the clivus forming a convex hump which may rise above the sella turcica. Secondary effects are a flattening of both posterior fossae and pituitary fossae and a narrowing and tilting of the foramen magnum. Such a deformity. may in theory be secondary to any bone-softening disease, but is commonest in Paget's disease. There is, however, a 'primary' deformity of very similar appearance, produced by congenital malformation of the basiocciput and neighbouring bones (Walsh et al., 194I). Names for the deformity, whether primary or secondary, are numerous - convexobasie (Léri, I913), kyphosis of the clivus (Dubois-Ferriére, I940), platybasia, basilar invagination, basilar impression and many others. Platybasia is a mistaken importation from anthropometry, and basilar impression is a mistranslation of 'basale Impression des Schadels,' used by older German authors for the primary lesion, so basilar invagination remains the least unsatisfactory English term.

The lesion in its milder forms is fairly common, but the brain, at least above the tentorium, can survive a good deal of distortion without clinical effect (Grünthal, I93 I). Below the tentorium the grosser degrees of the deformity can do considerable damage, the medulla, pons and cerebellum suffering in varying degrees, producing neurological effects which vary considerably in detail. It has recently been shown (Wycis, 1944) that an occipital decompression with high cervical laminectomy is a valuable measure for the relief of this condition.

Of cerebral effects the only one of any importance is the occasional appearance of epilepsy which, as Mufson and Chodoff (1946) have shown, is only likely to appear in those inherently predisposed to epilepsy. Paget himself remarked on the preservation of the intellect in the presence of gross cranial deformity.

\subsection{Spinal CoRD}

Paraplegia is not very rare; Schwarz and Reback (I939) published nine cases and Turner (I940) seven. A progressive compression of the cord by thickening of the surrounding bone is the usual mechanism. The majority occur in the thoracic region, where the spinal canal is narrowest, but two cervical cases are recorded with actual displacement and a more sudden onset (Garcin et al., 1937; Whalley, 1946). In most of the reported cases the Paget's. disease has been relatively localized, but in our only example the lesion was terminal in a long-standing and very extensive case (the case A.H. of Edholm et al., 1945).

The gradual onset, thoracic level, and ' girdle sensations' due to root pressure (Turner distinguishes these from root pains, which are rare in Paget's disease) are of importance in diagnosis. Laminectomy, first recorded by Wyllie in $192 \mathrm{I}$, is a remarkably successful procedure, at least 75 per cent. of recorded cases being cured or substantially improved, and it should be carried out wher possible. As Turner records, the disease may recur after years of freedom. Occasionally para plegia may be due to osteosarcoma supervening on Paget's disease (Campbell and Whitfield, 1943).

\subsection{Nose, Sinuses and Jaws}

Though relatively infrequent, involvement of the facial bones in Paget's disease does undoubtedly occur (Glickman and Glidden, 1942). The important secondary effects of these are :-

I.33 I. Nasal obstruction. The relative importance of this and of olfactory nerve involvement in producing anosmia has not been determined.

1.332. Sinus obstruction. The paranasal sinuses may be compressed and even obliterated, or obstruction of their ducts may cause sinusitis (Gregg, 1926; Moore, 1927; Brunner and Grabscheid, 1938 ; Harris, 1944). Frontal sinusitis from this cause is probably not uncommon one of our cases presented in this way.

1.333. Displacement and loss of teeth.

I.334. Pseudo-tumour of the maxilla. Enlargement of the maxilla due to Paget's disease is not very rarely misdiagnosed as tumour, and extensive operations have been undertaken under this diagnosis. Neither radiography nor biopsy has always avoided the error. One might almost exalt into a syndrome the succession of diagnoses of tumour of the maxilla, osteoporosis cranil 


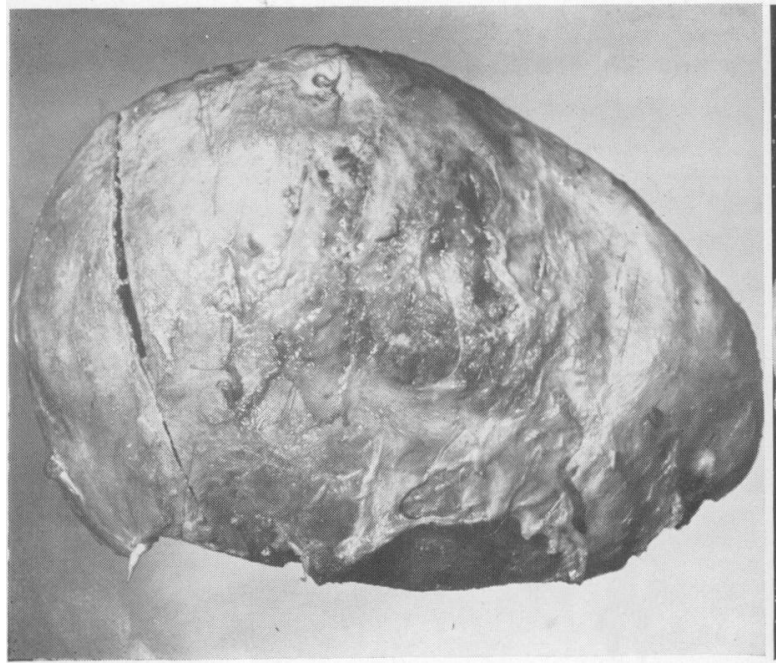

(a)

Fig. I.-Skull cap in a case of Paget's disease. The lateral view (a) shows a half-made saw cut ; the skull cap broke away from the base before it could be completed. The deep grooves of the meningeal vessels are well seen in the view (b) from below. They show that vessels can be surrounded by Paget's bone without being compressed.

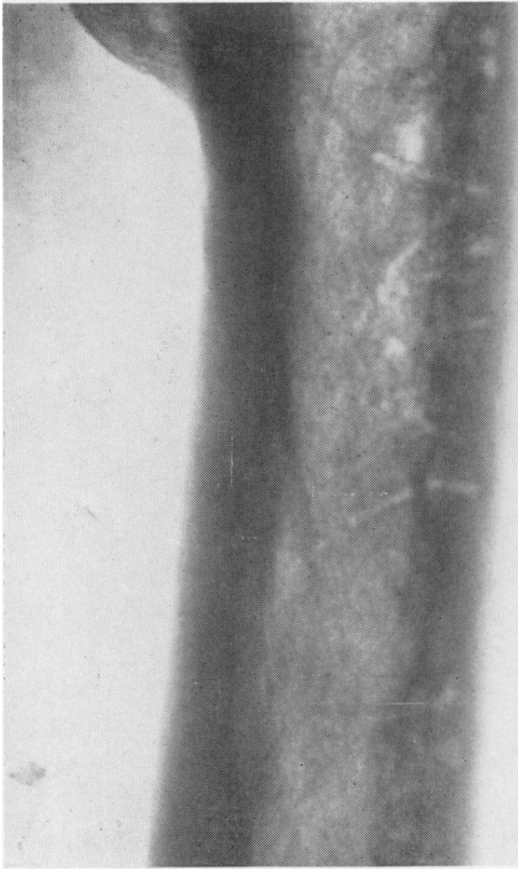

Fig. 2.-Transverse 'infractions' of the shaft of the femur; note that they avoid the concave margin and (in this case) the outermost zone.

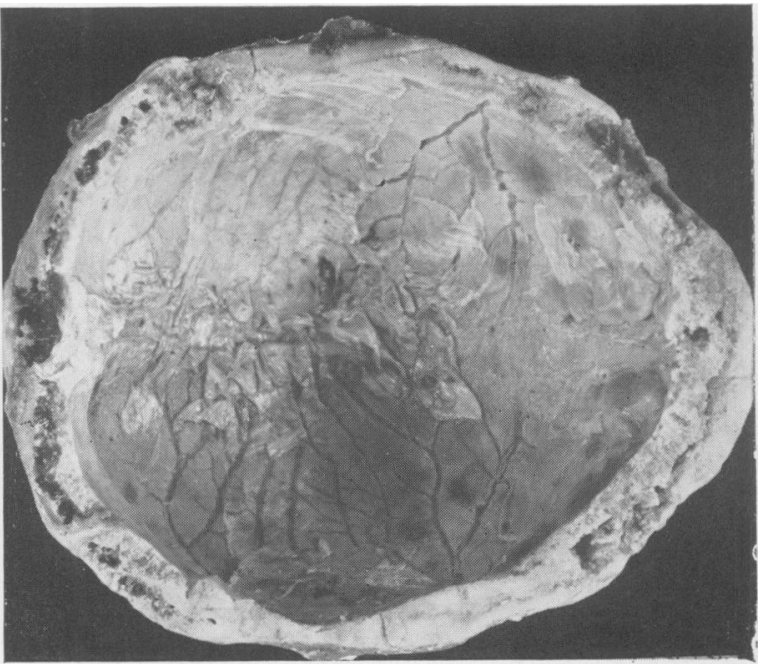

(b)

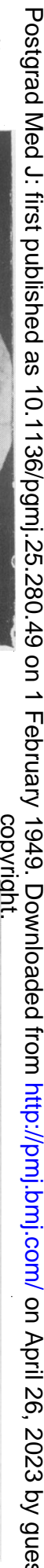

Fig. 3.-Fracture of the great trochanter; an unusual fracture in Paget's disease, but in the usual neighbourhood. The disease in the femur is early, in the pelvis more advanced. 

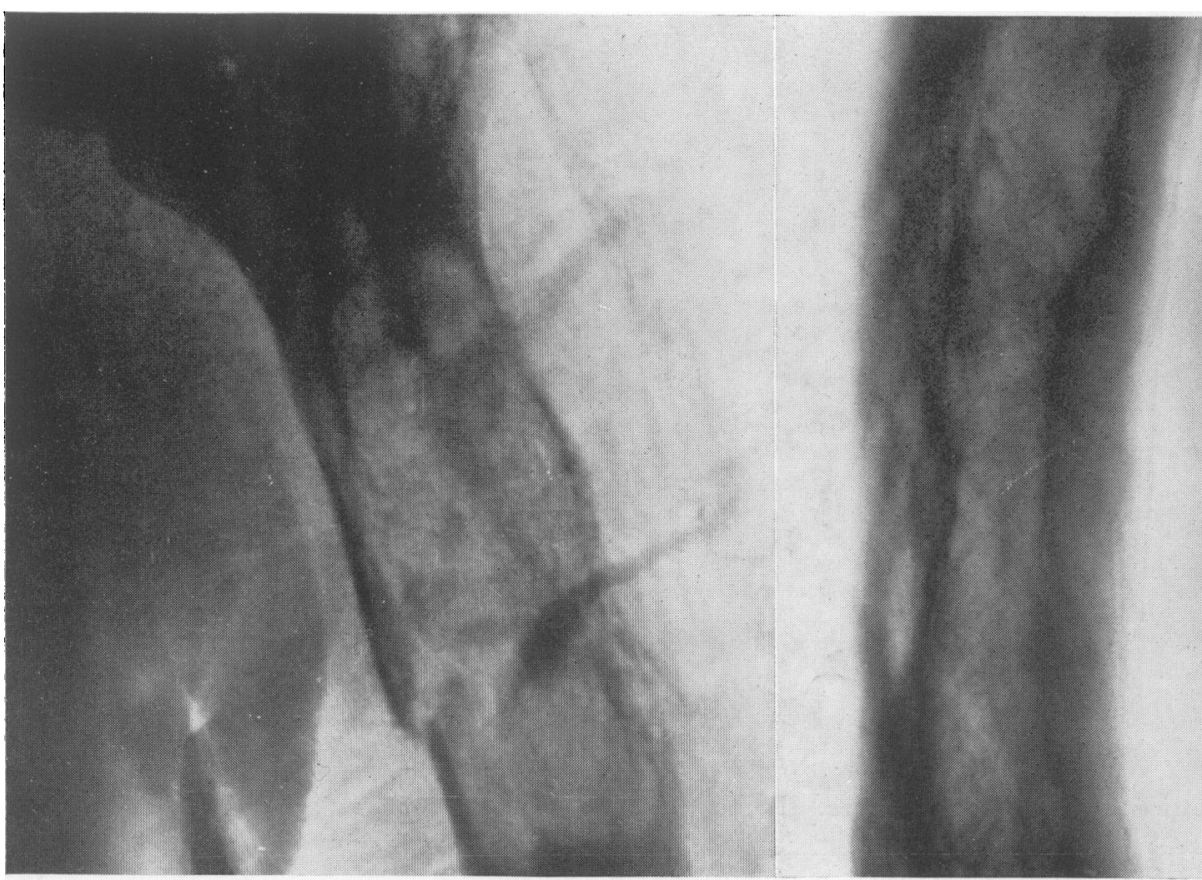

Fig. 4.-Pathological fracture due to an osteolytic endosteal osteosarcoma arising in a humerus affected by Paget's disease.
Fig. 5.-Calcified femoral artery in a case of generalized Paget's disease. Note the ring shadows of a Mönckeberg's sclerosis ; the lumen is clear. (To obtain a satisfactory print from this X-ray different $\overline{0}$. exposures of the two halves were necessary; it was thought wiser to make this obvious in the finished print.)

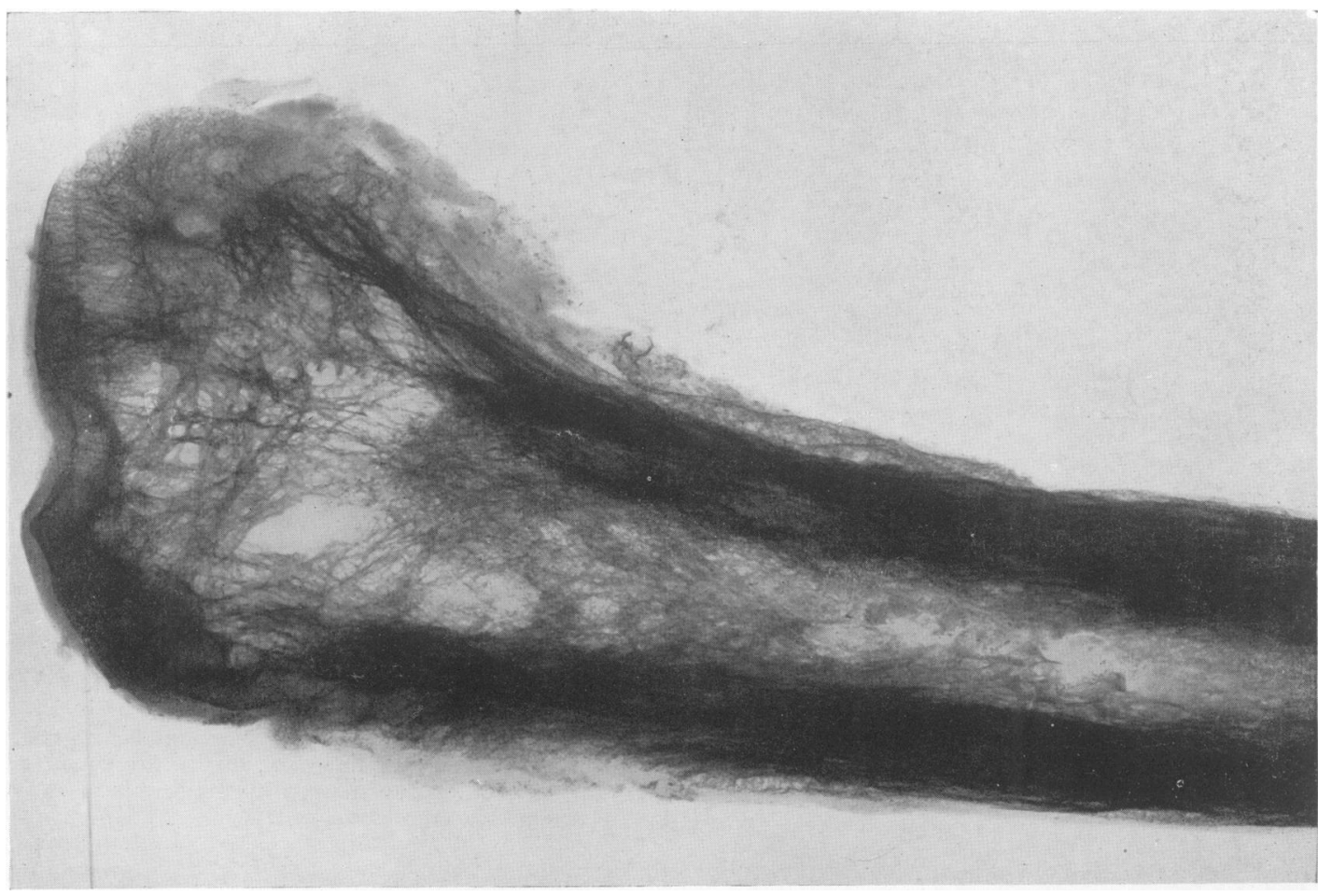

Fig. 6.-The femur of the case illustrated in Figs. 7, 8 and 9, showing typical Paget's disease. 


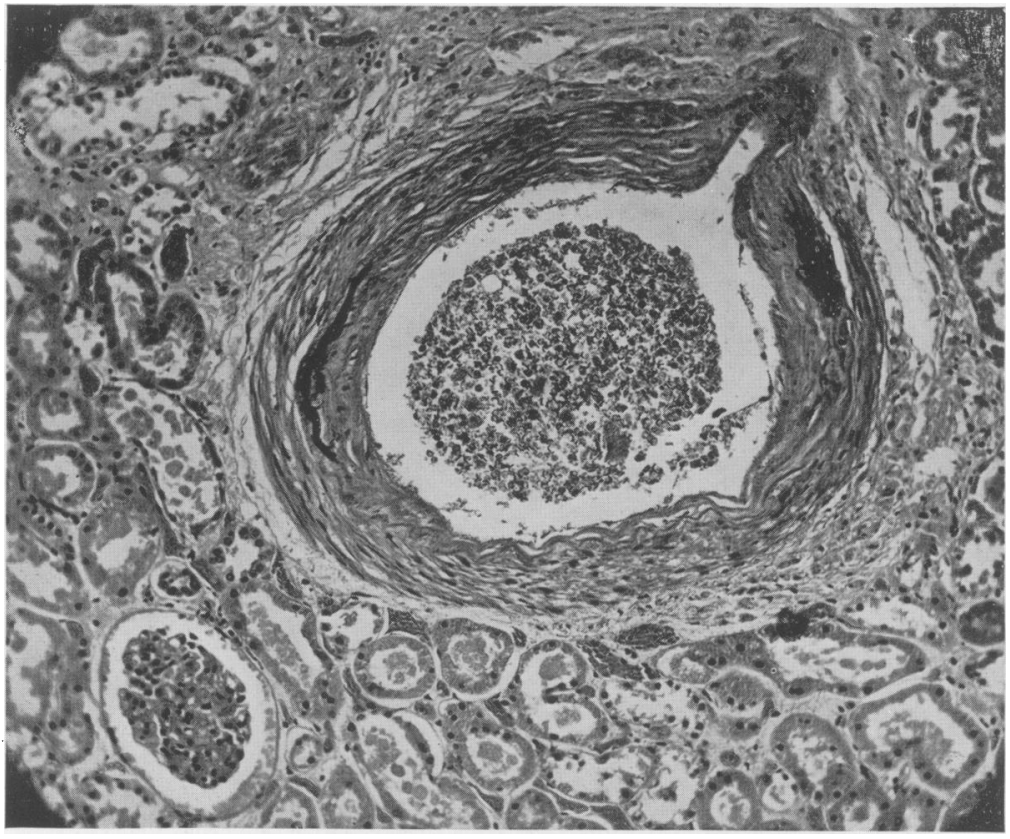

FIG. 7.-Medial calcification in an artery of the renal boundary zone.

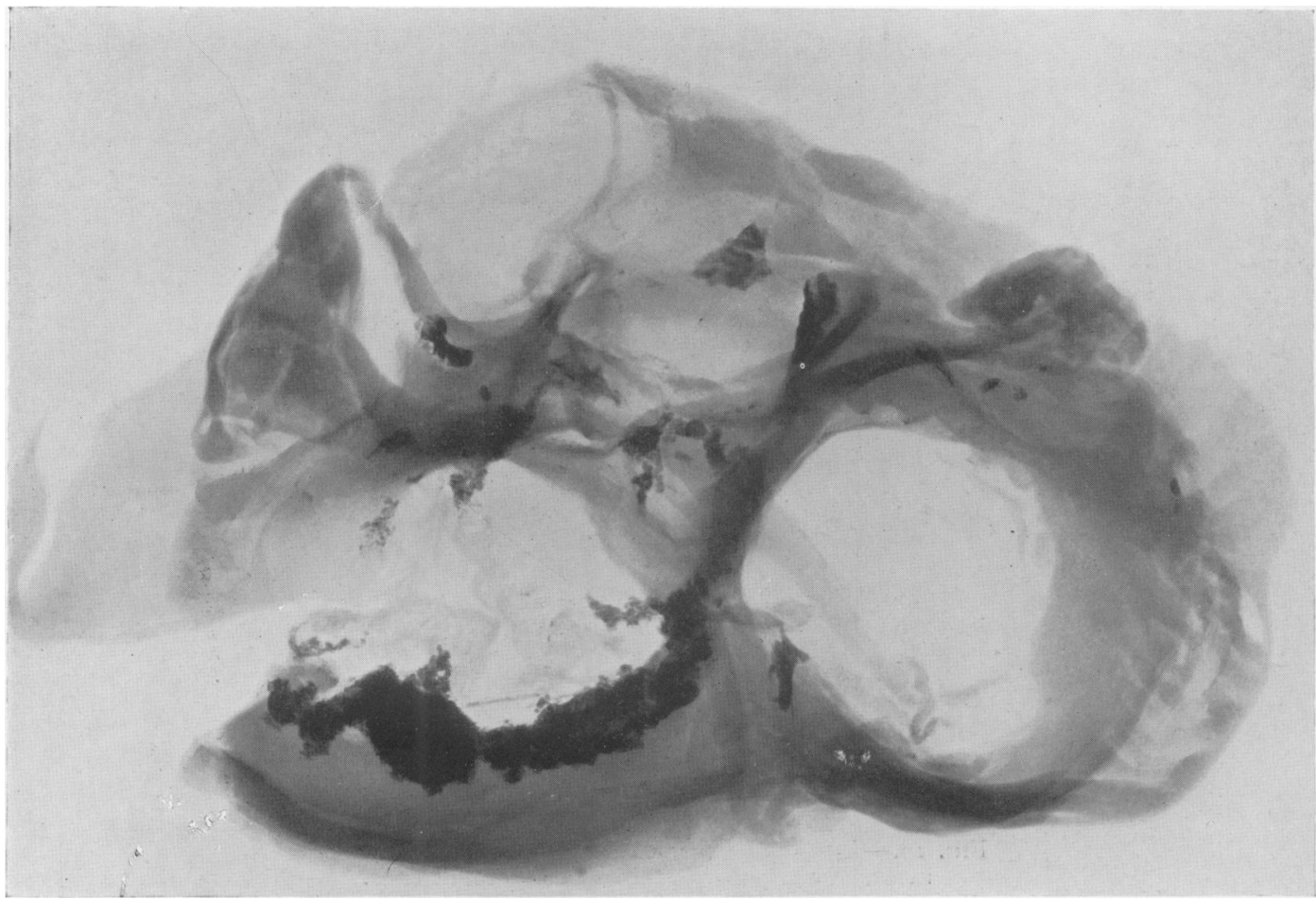

FIG. 8.-X-ray of a transverse slice of the heart including the valves, showing irregular calcification involving especially the posterior part of the mitral ring and extending on to the membranous septum. There is also some calcification of the coronary arteries. 

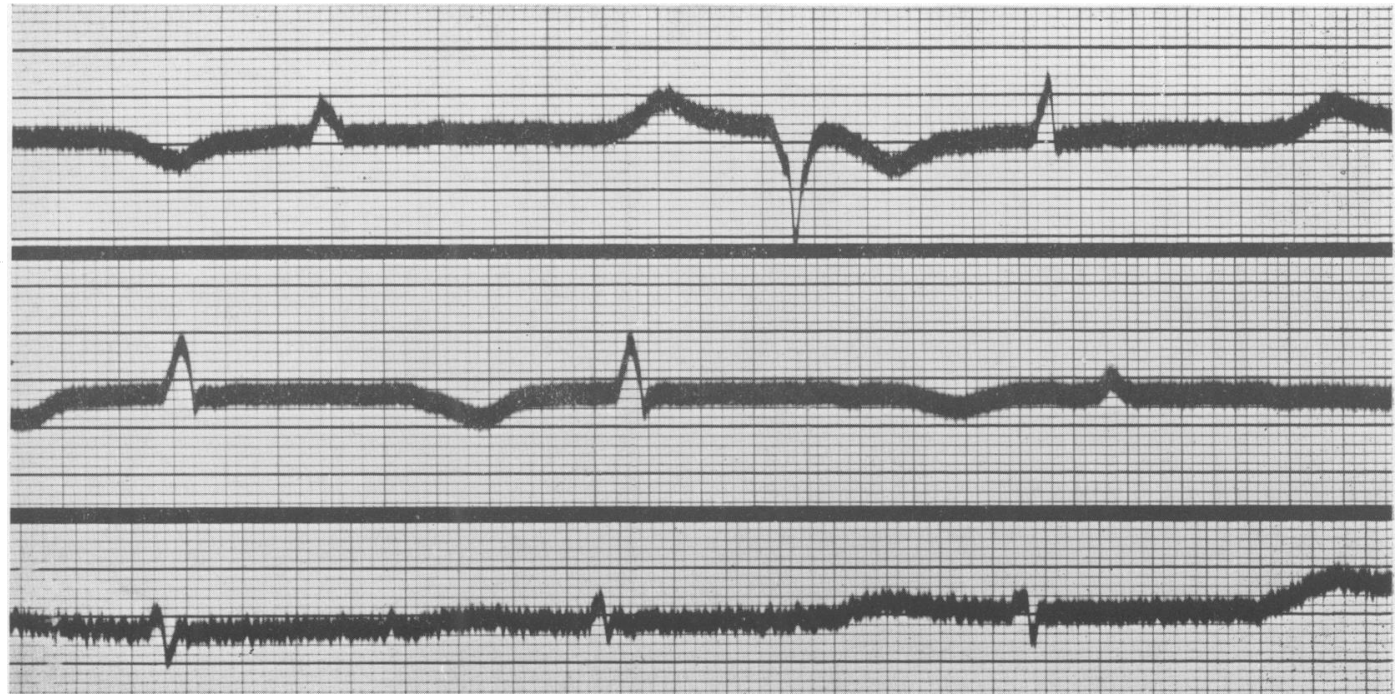

Fig. 9.-Electrocardiogram (standard leads) showing complete heart block, the result of the lesion shown in Fig. 8.

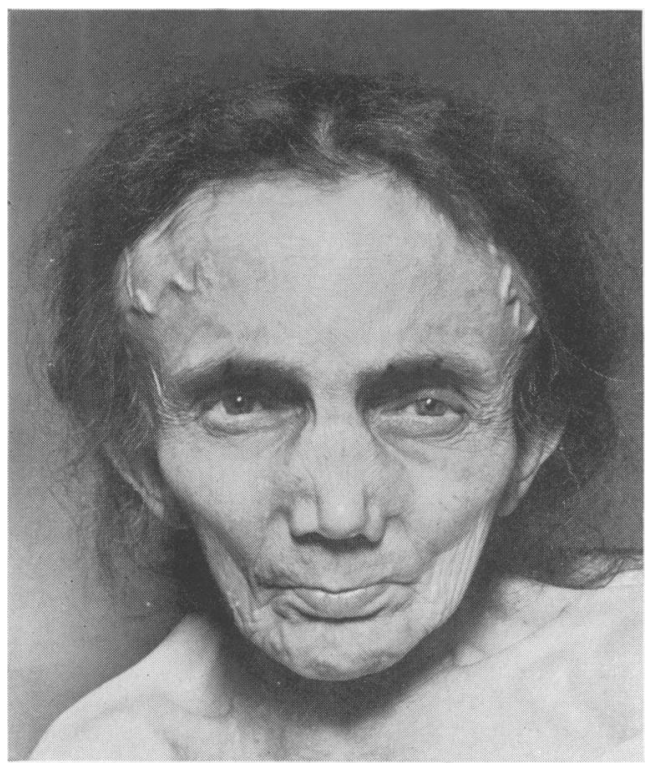

FIG. 10.-A case of Paget's disease with skull involvement, showing the prominent temporal arteries. 
circumscripta and Paget's disease of the skull (Kasabach and Gutman, 1937; Elkeles, 1947). We have recently seen such a case, now in the second stage.

Some of the difficulties of diagnosis of Paget's disease in this region are due to its early appearance. Whether skull and facial deformities bring patients to their doctor earlier than lesions elsewhere, or whether there is some real variation in the natural history of the disease is uncertain. It is clear, however, that in nearly all cases in which Paget's disease is diagnosed in the 20's and 30's it is the skull which is chiefly involved. The old controversy over hyperostosis cranialis and the more recent one over osteoporosis cranii circumscripta both refer to conditions now recognized (Prince, 1902 ; Kasabach and Dyke, r932) as forms of Paget's disease, and both derive from the apparent age difference.

\subsection{Thoracic Deformity}

Respiratory embarrassment and cor pulmonale due to thoracic deformity might be expected to be common and the earliest accessible case (Wilks, I869) was believed to have died in this way. Subsequent experience shows it to be rare. Loeschke (1926) showed that it is the sharply angulated spinal deformity which is especially likely to cause cardiorespiratory effects, and the kyphosis of Paget's disease is usually a smooth curve.

\subsection{Hypercalcaemic Episodes and Metastatic Calcification}

No metabolic disorders except those of the calcium phosphate complex have been established in Paget's disease. Of those established only the raised alkaline phosphatase (Kay, I930) is constant and characteristic. The blood calcium and phosphate are usually normal, and there is nothing to suggest that any general disorder of calcium metabolism lies at the root of the disease. It has recently been shown, however, that it can be very readily disturbed in at least two ways :-

(a) By immobilization. Reifenstein and Albright (1944) studied two cases of generalized Paget's disease who suffered fractures. Both were kept on a normal hospital diet with plenty of milk. In both; the blood calcium and phosphorus rose, phosphatase dropped, urinary calcium rose, and there was marked gastric distress and evidence of increasing renal insufficiency. Both appeared to have been saved from renal failure only by forced fluids and a low calcium diet.

(b) By Vitamin D. Wells and Holley (1942) and Seligman and Nathanson (1945) described cases in which doses of Vitamin $D$ were given which, though large, were within therapeutic limits. Both developed extensive metastatic calcification and died.

The practical lessons of these two observations are obvious. Vitamin D, though necessary for the bed-ridden patient, must be given in minimal doses. Immobilization is dangerous. If it is inevitable, extra fluids and a low calcium diet must be given. Episodes of hypercalcaemia, however caused, may well be the origin of the various metastatic calcifications now to be described, which are common in Paget's disease. It is to be noted that the regions involved are those in which either abundant arterial blood or minimal metabolic activity produce a low $\mathrm{CO}_{2}$ tension and a low calcium solubility.

\subsection{Arterial Calcification}

The radiographic observation of calcified arteries was first made by Béclère in IgOI. O'Reilly and Race (1932) found it in 40 per cent. of their cases. The calcification is a Mönckeberg's sclerosis, a medial calcification (Figs. 5 and 7 ), and the arteries are not obstructed. Clinically the lesion is of no importance.

\subsection{Heart Valve Calcification and Heart Block}

Paget's original case developed a calcific mitral stenosis during the course of his illness. Harrison and Lennox (1948) found such lesions in 40 per cent. of cases coming to autopsy, five times the frequency in controls of the same age and sex. The mitral and aortic valves only are involved; calcium is not deposited from venous blood. Probably the lesion begins by deposition of calcium salts in an area of hyaline collagen degeneration and once established tends to spread. The valve lesions themselves are rarely important, but the process sometimes spreads into the interventricular septum and interrupts the bundle of His (Figs. 8 and 9). The relation of heart block to Paget's disease in this way has been only recently recognized (Windholtz and Grayson, I947 ; Harrison and Lennox, I948).

Heart block of this type may be commoner than the lack of reported cases would suggest. There are many unexplained deaths from ' heart failure' in the literature of Paget's disease, and some of these (Higbee and Ellis, I9I I ; Clegg, I937) had calcified septa.

\subsection{Calcification of Avascular Structures}

These are common and too various for detail. Scars of all sorts, old fibroids, old goitres, and the pineal body are the commonest.

\subsection{Urinary Calculi}

'The significance of the association of Paget's 
disease and stone is doubtful. Goldstein and Abeshouse (1935) reported seven cases with both conditions, and Io per cent. of Snapper's (1943) and 4.9 per cent. of Newman's (1946) cases had calculi. These figures are weighted by the frequency with which unsuspected Paget's disease is discovered during routine $\mathrm{X}$-ray for stone, the lumbar spine and pelvis being the commonest sites of such unsuspected disease.

The high incidence of stone in hyperparathyroidism is, of course, due to the high urinary excretion of calcium (Barney and Sulkowitch, 1937). No such hyperexcretion occurs in Paget's disease, and it may be doubted whether the occasional episodes of hypercalcaemia already described can be sufficient to produce stones. Even in hyperparathyroidism the incidence of stone varies geographically (Wilder and Howell, 1936) and statistics on the subject would be difficult to assess. Our own figures show one case of certain stone in 88 of Paget's disease (I.I per cent.) against a general incidence of 0.4 per cent. of stones, hardly very conclusive figures. The incidence of stone in Paget's disease must be of minor importance.

\subsection{Endocrine Disorders}

One must mention here only to dismiss the observations of Moehlig and Adler (1937) who found a high incidence of diabetes and gigantism in relatives of their patients, and who ascribed the disease to a pituitary disorder. Their arguments are, to say the least, unconventional and their facts have not been confirmed.

Davie and Cooke (1937) recorded a deficiency of oxyphil cells in the parathyroids in their two cases. The observation has been confirmed but its significance is quite uncertain.

\subsection{High Output Heart Failure; the Arteriovenous Shunt}

Redman (I889) seems to have been the first to point out the existence of any circulatory abnormality. In a brief note in a special number of the Illustrated Medical News devoted to the disease (with many interesting, if repetitive, articles by famous men), he produced a single sphygmograph showing a pulse which he describes as "of high tension, regular, and visibly pulsatile.' French authors around the turn of the century, beginning with Pierre Marie (I892) continued to note the frequency of vascular abnormalities, especially heart murmurs ; such murmurs often derive from the calcific valve lesions already noted, but this is not the whole story. Klippel and Weil (1908) noted warm skin and dilated veins in the affected leg of a man with unilateral disease, but quite misinterpreted the findings. Kay et al. (1934) noted the frequency of high pulse pressures, and their carefully recorded series bears the fullest witness 3 to the frequency of circulatory abnormalities.

In I943 a man was admitted to Hammersmith $\subseteq$ Hospital under Prof. McMichael with general- $\overrightarrow{\vec{F}}$ ized Paget's disease and the signs of congestive $\frac{\rho}{\square}$ heart failure. The two were then regarded $\frac{\mathrm{C}}{0}$ as coincidental. About this time a great deal $\frac{\bar{\sigma}}{\bar{D}}$ of work was in progress in the hospital on cardiac $\frac{\vec{D}}{\nabla}$ catheterization, cardiac output and the varieties of $\cong$ heart failure (Sharpey-Schafer, I944; McMichael के and Sharpey-Schafer, 1944). On readmission of $\vec{O}$ the patient in 1944 it was at once recognized that $\overrightarrow{-}$ his warm extremities, full pulse and capillary $\vec{\sigma}^{\circ}$ pulsation were evidence of high cardiac output. $\frac{D}{0}$ The jugular venous blood was bright red in 3 . colour. Cardiac catheteriżation confirmed the î. high output ( 13 litres per minute instead of the of normal 4-5 litres). The conditions were those met $\mathbb{O}_{0}^{\circ}$ with in a gross arteriovenous shunt. Surgical experience of the vascularity of the bone in other 0

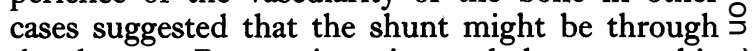
the bone. By an ingenious plethysmographic $\vec{r}$ technique it was shown that the blood flow through $\frac{1}{0}$ affected bones was 20 times that through the normal. This was found to be adequate to explain the raised output and the heart failure (Edholm Howarth and McMichael, 1945).

Severe congestive heart failure from this cause may be uncommon, but a high proportion of cases show some evidence of raised cardiac output. If one excluded the prominence of some arteries due to the high blood flow through them, and the medial calcification of others, little is left of the $\stackrel{\mathbb{Q}}{\varrho}$ 'arteriosclerosis' often described in Paget's $\overrightarrow{\overrightarrow{0}}$ disease. The prominent temporal arteries so often $\frac{0}{3}$ seen in cases with skull involvement (Fig. ro) probably derive from both causes. Arteriosclerosis in the sense of occlusive vascular disease is no commoner than in the general population.

\subsection{Varicose Veins}

Varicose veins and varicose uicer occur fre- $\delta$ quently, especially in earlier accounts of the disease (e.g. Hall, 1897; Oettinger and Agasse-Lafont, 옹 1905). This may be mere coincidence, but it $\rightarrow$ seems possible that the veins of the leg may be distended by the constant excessive venous return, $N$ and an enlarged or bowed tibia may increase the frequency of varicose ulcer.

\section{Summary}

The more important of the complications of 0 Paget's disease of bone listed here are :-

(a) Fracture.

(b) Osteosarcoma.

(c) A variety of pressure effects on the nervous system, of which deafness is important because of 
its frequency, and paraplegia and basilar invagination because they can be treated surgically.

(d) A tendency to hypercalcaemia and various metastatic calcifications.

(e) Heart block due to septal calcification.

(f) High output heart failure due to the shunt through the vascular bones.

\section{ACKNOWLEDGEMENTS}

Professor J. McMichael and Dr. C. V. Harrison were responsible for my original interest in this subject and have given a great deal of help. Professor E. P. Sharpey Schafer, Dr. Duncan White and Dr. J. C. Corall lent radiographs, and Mr. E. V. Willmott overcame considerable technical difficulties in their reproduction. Mr. B. B. Bonner of the records department is partly responsible for the estimates of frequency of complications in our own material. To all these my thanks are due. Figs. 6-9 are reproduced by kind permission of the Editor of the British Heart fournal.

\section{BIBLIOGRAPHY}

BADGELEY, C. E., and BATTS, M. (194r), Arch. Surg., Chicago, 43, $54 \mathrm{I}$.

BARNEY, J. D., and SULKOWITCH, H. W. (1937), f. Urol., 37, 746 .

BECLERE, M. A. (1901), Bull. Soc. med. Hop., Paris, 3me Ser., 18, 929.

BRUNNER, H., and GRABSCHEID, E. (1936/7), Virchows Arch., 298, 195.

BRUNNER, H., and GRABSCHEID, E. (1938), Virchows Arch., 301, 237.

CAMPBELL, E., and WHITFIELD, R. D. (1943), N.Y. St. F. Med., 43, 931 .

CASS, E. E. (1939), Proc. R. Soc. Med., 32, 760.

CLEGG, J. F. (1937), Lancet, ii, 128.

COLEY, B. L., and SHARP, G. S. (1931), Arch. Surg., Chicago, 23, 918 .

DAVIE, T. B., and COOKE, W. E. (1937), Brit. F. Surg., 25, 299.

DUBOIS-FERRIERE, H. (1940), Schweiz. Z. alg. Path. Bakt., $3,22$.

EDHOLM, O. G., HOWARTH, S., and MCMICHAEL, J. (1945), Clin. Science, 5, 249.

ELKELES, A. (1947), Proc. Roy. Soc. Med., 40, 466.

GARCIN, R., VARAY, A., and DIMO, H. (1937), Rev. Neurol., 67, $76 \mathrm{I}$.

GLICKMAN, I., and GLIDDEN, H. S. (1942), f. Amer. dent. Assn., 29, 2144.

GOLDSTEIN, A. E., and ABESHOUSE, B. S. (1935), Amer. $\mathcal{F}$. Surg., 30, 359.

GREGG, D. (1926), Arch. Neurol. Psychiat., 15, 613.

GRUNTHAL, E. (1931), Z. ges. Neurol. Psychiat., 136, 656.

GUillain, G., and MESSIMY, R. (1939), C. R. Soc. Biol., Paris, 13I, 499.

GUTMAN, A. B., and KASABACH, H. (1936), Amer. f. med. Sci., 191, 361.

HARRIS, H. E. (1944), Cleveland Clin. Quart., 11, 74.

HARRISON, C. V., and LENNOX, B. (1948), Brit. Heart. $\mathcal{f}$ Io, 167 .
HIGBEE, W. S., and ELLIS, A. G. (I9I1), f. med. Research, 24, 43.

HALL, F. DE H. (1897), Trans. med. Soc., London, 19, 418.

JAFFE, H. L. (1933), Arch. Path., 15, 83.

JENKINS, G. J. (1923), F. Laryng. Otol., 38, 344.

KASABACH, H. H., and DYKE, C. G. (1932), Amer. F. Roentgenol., 28, 192.

KASABACH, H. H., and GUTMAN, A. B. (1937), Amer. $\mathcal{f}$. Roentgenol., 37, 577.

KAY, H. D. (1930), ₹. biol. Chem., 89, 249.

KAY, H. D., SIMPSON, S. L., and RIDDOCH, G. (1934), Arch. intern. Med., 53, 208.

KLIPPEL, J., and WEIL, L. (1908), Rev. neurol., 16. 1228.

KNAGGS, R. L. (1926), Brit. F. Surg., 13, 206.

KOLLER, F. (1946), Helv. med. Acta., 13, 389.

LOESCHKE, H. (I928), in Henke-Lubarsch 'Handbuch,' Berlin Bd., 3, 1, p. 611 .

LEHOCZKY, T. (1939), Rev, neurol., 71, 727.

LERI, A. (I9I3), Nouv. Iconogr. Salpet., 26, 452.

MCMICHAEL, J., and SHARPEY-SCHAFER, E. P. (1944), Quart. F. Med., 37, 123.

MARIE, P. (1892), Bull. Soc. med. Hop., Paris, 3me Ser., 9, 416.

MOEHLIG, R. C., and ADLER, S. (1937), Surg. Gynec. Obstet., 64, 737 .

MOORE, S. (1927), Ann. Otol., St. Louis, 36, 662.

MUfSON, J. A., and CHODOFF, P. (1946), Ann. intern. Med. 16, 762.

NEWMAN, F. W. (1946), ₹. Bone 7 t. Surg., 28, 798.

NICHOLS, B. H., and RAINES, J. R. (194I), Cleveland Clin. Quart., 8, 139.

OETTINGER, L., and AGASSE-LAFONT, E. (1905), Nouv. Iconogr. Salpet., 18, 292.

O'REILLY, J. J., and RACE, J. (1932), Quart. .. Med., 25, 47 I.

PACKARD, F. A., STEELE, J. D., and KIRKBRIDGE, T. S. (1901), Trans. Assoc. Amer. Phys., 16, 666.

PAGET, J. (1877), Med. Chir. Trans., 60, 37.

PAGET, J. (1889), Illust. med. News, 2, 181.

PLATT, H. (1946/7), Brit. F. Surg., 34, 232.

POSTIC, S. (1940), Arch. Ophthal., 14I, 564.

PRINCE, M. (1902). Amer. F. med. Sci., n.s., r24, 796.

REDMAN, W. E. (1889), Illust. med. News, $2,189$.

REIFENSTEIN, E. C. JK., and ALBRIGHT, F. (1944), New Engl. F. Med., 70, 295.

ROGERS, M. H., and ULLIN, R. V. (1936), F. Bone ft. Surg., I8, 914 .

SCHMORL, G. (1926), Verh. dtsch. path. Ges., 21, 71 .

SCHMORL, G. (1930), Verh, dtsch. path. Ges., $25,205$.

SCHMORL, G. (1932), Virchows Arch., 283, 694.

SCHWARZ, G. A., and REBACK, S. (1939), Amer. F. Roentgenol., 42. 345 .

SELIGMAN, B., and NATHANSON, L. (1945), Ann. intern. Med., 23, 82 .

SHARPEY-SHAFER, E. P. (1944), Clin. Sci., 5, 125.

SNAPPER, I. (1943), 'Medical Clinics on $B_{1}$ Diseases,' New York.

SUGARBAKER, E. D. (1940), Amer. F. Surg., 48, 4I4.

SUMNEY, T. J., and PRESSLEY, C. L. (1946), Ann. Surg., 123, 135.

TAMARI, M. (194I), Ann. Otol., St. Louis, 51, I70.

TURNER, J. W. A. (1940), Brain, 63, 32 I.

VON ALBERTINI, A. (1929), Virchows Arch., 268, 259.

WELlS, H. G., and HOLLEY, S. W. (1942), Arch. Path., 34, 435.

WALSH, M. N., CAMP, J. D., and CRAIG, W. MCK. (I94I), Proc. Mayo Clin., 16, 449.

WHALleY, N. (1946), F. Neurol. Neurosurg. Psychiat., 9, 84.

WILDER, R. M., and HOWELL, L. P. (1936), Ұ. Amer. med. Ass., IO6, 427.

WILKS, S. (1869), Trans. path. Soc., London, 20, 273.

WINDHOLTZ, F., and GRAYSON, C. (1947), Amer. $y$. Roentgenol., 58, $5 \mathrm{I}$ I.

WYCIS, H. T. (I944), $\mathcal{F}$. Neurosurg., 1, 299.

WYLLIE, W. G. (I921), Brain, 46, 336. 